\title{
Influence of Deuterium-Depleted Water on Hepatorenal Toxicity
}

\author{
Dzhimak Stepan Sergeevich, ${ }^{1}$ Basov Alexandr Alexandrovich, ${ }^{2}$ Elkina Anna Anatolyevna, ${ }^{1,}$ Fedulova \\ Liliya Viacheslavovna, ${ }^{3}$ Kotenkova Elena Alexandrovna, ${ }^{3}$ Vasilevskaya Ekaterina Romanovna, ${ }^{3}$ Lyasota \\ Oxana Mikhailovna, ${ }^{1}$ and Baryshev Mikhail Gennadievich ${ }^{1}$ \\ ${ }^{1}$ Department of Radiophysics and Nanotechnology, Kuban State University, Krasnodar, Russia \\ ${ }^{2}$ Department of Fundamental and Clinical Biochemistry, Kuban State Medical University, Krasnodar, Russia \\ ${ }^{3}$ Experimental Clinic - Laboratory of Biologically Active Substances of Animal Origin, The V.M. Gorbatov All-Russian Meat Research Institute, Moscow, Russia \\ "Corresponding author: Elkina Anna Anatolyevna, Kuban State University, 350040, St Stavropolskaya 149, Krasnodar, Russia. E-mail: 013194@mail.ru
}

Received 2016 December 16; Accepted 2017 May 03.

\begin{abstract}
The objective of the current study was to evaluate the influence of deuterium-depleted water (DDW) consumption on healthy animals and animals with hepatorenal toxicity. The influence of deuterium-depleted water on hepatorenal toxicity was investigated in Wistar rats. Deuterium-depleted water consumption during 42 days caused changes in isotopic D/H composition of rats' plasma and lyophilized tissues of internal organs (liver and kidney). Moreover, deuterium-depleted water influenced plasma biochemical parameters. Concentration of creatinine and bilirubin, as well as aspartate aminotransferase and alanine aminotransferase activities were reduced in plasma of rats with hepatorenal toxicity. Deuterium-depleted water consumption during 42 days influenced the body and internal organ weights while integral index of chronic intoxication did not increase in rats with chronic intoxication. It was also revealed that deuterium-depleted water consumption did not display any toxic effects.
\end{abstract}

Keywords: Hepatorenal Toxicity, Deuterium, Liver, Detoxification, NMR Spectroscopy, Isotopes, Plasma, Water

\section{Background}

Stable isotope concentrations of biogenic elements in food depend on its origin (1-3). Therefore, isotope concentrations are strongly fluctuated in animal organism (4). Nowadays, analysis of stable isotope concentrations is a new method for assessment of food trophic structure and animal diets (5).

Fractionation during water Earth cycle caused changes of deuterium concentrations in natural waters $(6,7)$. Therefore, the relationship between water consumers and sources as well as the study of stable isotope concentrations in tap water is an important subject.

Deuterium-depleted water (DDW) is ${ }^{1} \mathrm{H}_{2}{ }^{16} \mathrm{O}$ water isotopologue formed by light stable isotopes of hydrogen and oxygen. Furthermore, international standard mean ocean water (SMOW) and SLAP recorded the basic standards of isotopic composition in hydrosphere, including concentration of water molecules containing heavy isotopes $(\mathrm{D}$, $\left.{ }^{17} \mathrm{O},{ }^{18} \mathrm{O}\right)$. According to the SMOW, absolute content of deuterium $(\mathrm{D} / \mathrm{H})$ in the ocean water is $155.76 \pm 0.05 \mathrm{ppm}$ or $0.0 \%$, while in the SLAP standard, the mean is $89.00 \mathrm{ppm}$ or $-428.0 \%$

Deuterium-depleted water consumption leads to re- duction of deuterium concentration in liquids and tissues of organisms due to isotopic exchange reactions. These reactions may impact cellular cycle and cell proliferation (8), stimulate the reproductive function and have radioprotective response without any toxic effects on the organism (9). Deuterium concentration in the plasma of healthy animals is enriched with 3 to 6 ppm compared with drinking water (10). Ordinary water replacement to "heavy" results in electrical conductivity reduction in electrolyte solutions, and changes in structure and properties of DNA and proteins molecules. Dynamic short-term hydrogen (including deuterium) bonds are the most important for macromolecular structure and function. Structural and dynamic properties of cell membrane depend on qualitative and quantitative lipid composition and can be modified in the presence of heavy water (11).

Biochemical reactions leading to toxic substances accumulation in the body have a significant role in the development of hepatorenal toxicity. Previously, it was revealed that DDW could neutralize toxic effects of chromium, cadmium, and manganese (12).

Pathophysiological mechanisms of $\mathrm{D} / \mathrm{H}$ isotope composition that effect uncontrolled free radical reactions in organisms during hepatorenal toxicity are still not investi-

Copyright (c) 2018, Jundishapur Journal of Natural Pharmaceutical Products. This is an open-access article distributed under the terms of the Creative Commons Attribution-NonCommercial 4.0 International License (http://creativecommons.org/licenses/by-nc/4.0/) which permits copy and redistribute the material just in noncommercial usages, provided the original work is properly cited 
gated. Therefore, the study objective was to evaluate the influence of DDW consumption on healthy animals and animals with hepatorenal toxicity.

\section{Methods}

The study was carried out on 50 male Wistar rats (260 $\pm 25 \mathrm{~g}$ ) aged about 3 months old. Animals were kept under standard conditions (temperature of $20 \pm 3^{\circ} \mathrm{C}$, humidity $48 \pm 2 \%$, day/night (from 6:00 to 18:00/from 18:00 to 6:00), no more than six rats were placed in plastic cages (TECNIPLAST type IV S), and water and standard food (Labkorm, Russia) were available ad libitum. Hepatorenal toxicity was induced by intraperitoneal injection of 55\% carbon tetrachloride oil solution at a dose of $0.5 \mathrm{~mL} / \mathrm{kg}$ of body weight per day during 7 days. On the eighth day, gentamicin solution was intraperitoneally injected at a dose of 25 $\mathrm{mg} / \mathrm{kg}$ of body weight per day during the following 7 days. Nephropathy and chronic hepatitis leading to kidney and liver failure were reproduced on the 15 th day. The experiment lasted for 42 days and started at first injection. All the animals were cared under ethical considerations and the experimental protocol was duly approved by the bioethics commission (Protocol No 7/2015, approval dated 3.11.2015). Rats were randomly divided to 5 groups:

1- Group A - animals with hepatorenal toxicity model (negative “-" control) consumed water (-37\% deuterium) during all 42 days of the experiment;

2- Group B - animals with hepatorenal toxicity model consumed DDW (-743\% deuterium) during all 42 days of the experiment;

3- Group C - animals with hepatorenal toxicity model consumed DDW (-743\% deuterium) previously for 14 days and during all 42 days of the experiment;

4- Group D -intact animals (positive "+" control) consumed DDW (-743\% deuterium) during the 42 days of the experiment;

5- Group E - intact animals (control) consumed water (-37\% deuterium) during the 42 days of the experiment.

On the 42nd day, all rats were euthanized by gas displacement with carbon dioxide, according to the animal welfare rules. Body and internal organs were weighted; blood samples were collected for biochemical assays. Integral index of chronic intoxication (IICHI) were calculated for the liver and kidneys (13).

Isotopic composition of lyophilized organs was determined by a mass spectrometer DELTAplus provided with equipment for sample preparation of isotope hydrogen analysis H/Device (Finnigan, Germany) (13).

Deuterium-depleted water (-743\%) was obtained on the plant created by the Kuban State University (13). Mineralization of DDW was conducted by addition of mineral salts (mineralization 314 - $382 \mathrm{mg} / \mathrm{L}$ : hydro carbonates 144 - 180 $\mathrm{mg} / \mathrm{L}$, sulfates $<1 \mathrm{mg} / \mathrm{L}$, chlorides $60-76 \mathrm{mg} / \mathrm{L}$, calcium 6 $\mathrm{mg} / \mathrm{L}$, magnesium $3 \mathrm{mg} / \mathrm{l}$, sodium $50-58 \mathrm{mg} / \mathrm{L}$ and potassium 50 - $58 \mathrm{mg} / \mathrm{L}$ ). Furthermore, DDW mineral composition was identical with $-37 \%$ deuterium content water (14). Filtered standardized tap water (-37\%) was prepared on water treatment plant EMD Millipore RiOs ${ }^{\mathrm{TM}} 50$ (Merk Millipore, Germany).

Deuterium concentration in water and plasma were determined on impulse NMR spectrometer, JEOL JNM-ECA $400 \mathrm{MHz}$ (10).

Biochemical investigations were carried out with the semiautomatic analyzer BioChem SA (USA), according to the manufacturer's instructions (BioChem SA, High Technology INC, Walpole, MA USA). Concentration of total protein, creatinine, total bilirubin and activities of aspartate aminotransferase (AST), alanine aminotransferase (ALT) and alkaline phosphatase (ALP) were evaluated in rat plasma.

Statistical processing of the data was carried out by methods of variation statistics, and evaluation of the reliability of the differences in the average values (M) between groups was performed using non-parametric U-test (Mann-Whitney test, significant difference was considered for $\mathrm{P}<0.05)$.

\section{Results}

The daily water consumption was 18 to $27 \mathrm{~mL}$ per rat in all groups of animals. Deuterium concentration in rat plasma on the 42nd day is presented in Figure 1. The most significant deuterium reduction was observed in plasma of groups B, C and D (DDW consumption) compared with groups $\mathrm{A}$ and $\mathrm{E}$ (water with -37\% deuterium content). The revealed reduction was accompanied by significant replacement of protium to deuterium in plasma and tissues on the 42nd day (Figure 1).

On the 42nd day, isotopic hydrogen composition in lyophilized tissues was also studied. Deuterium decrease was noticed in groups B, C and D compared with control group E. Deuterium concentrations decreased 4.4, 4.3 and 1.6 times in lyophilized liver tissue and 3.7, 3.9, 1.5 times in lyophilized kidney tissue, respectively.

Observed dynamics corresponded to active isotope exchange reaction occurring between the body fluids and biological molecules in tissues of animals in the B, C and D groups (deuterium concentrations in tissues were in 1.5 to 3.3 times higher than in plasma).

Biochemical changes of all studied parameters had the same tendency and degree of development during the experiment. Persistent injuries of liver and kidney were confirmed with biochemical assays plasma of rats from group 


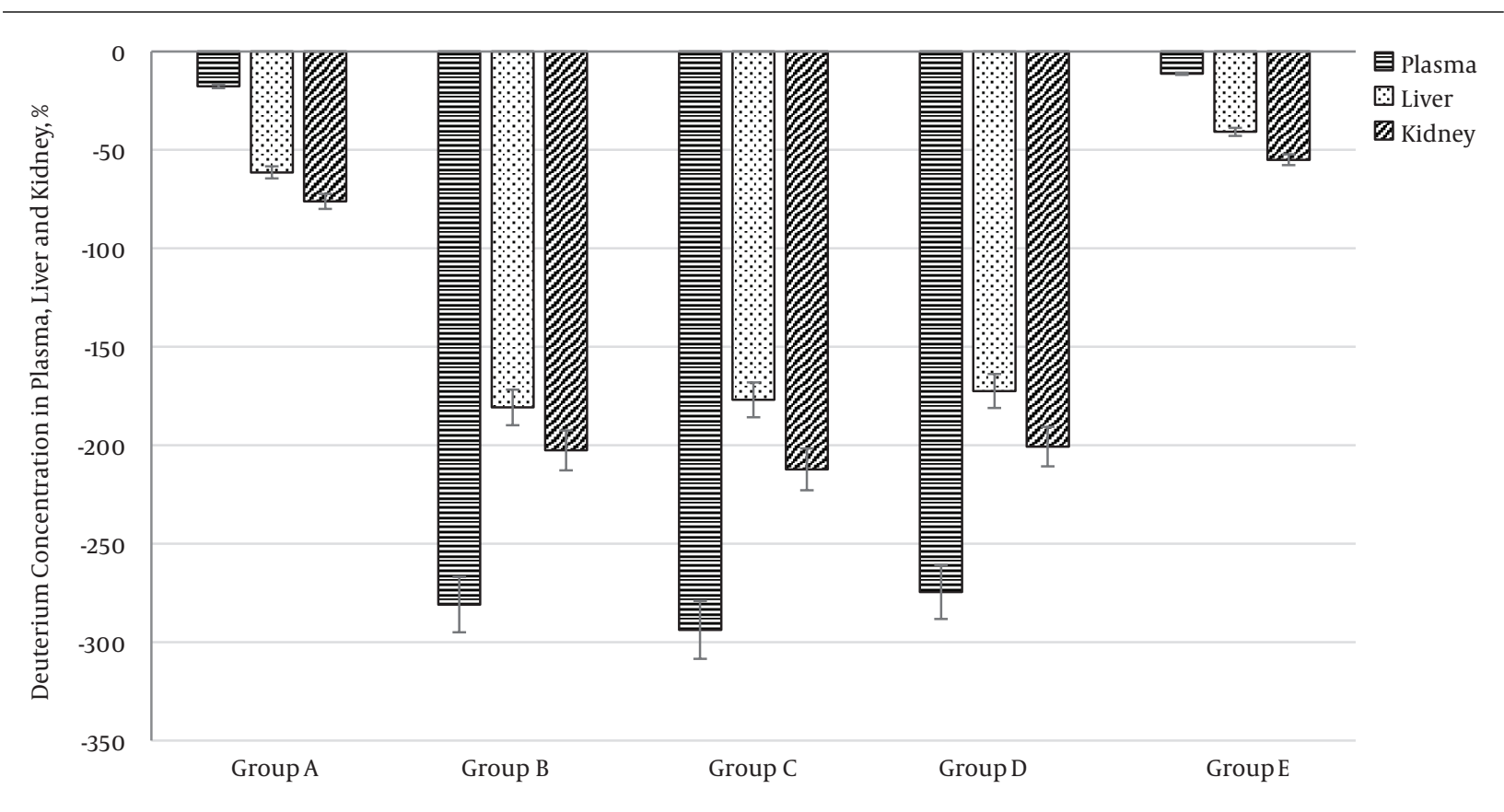

Figure 1. Deuterium concentration in plasma and lyophilized internal organs after the 42nd Day

A. Concentration of creatinine and activity of AST, ALT, and ALP in plasma of group A rats were increased by $57.1 \%, 42.9 \%$, $58.5 \%$, and $178.0 \%$, respectively (Table 1 ).

It was also found that less serious metabolic disorders were observed in rats consuming DDW (groups B and C) than in negative controls (group A) (Table 1).

Autopsy examination on the 42nd day revealed that in internal organs of groups B, C, D, and E, pathological processes were absent. The liver had homogeneous maroon color and elastic consistency. Liver of rats from group A was slightly enlarged and had homogeneous color.

The weight of liver and kidney was different between groups of experimental and control rats (Figure 2).

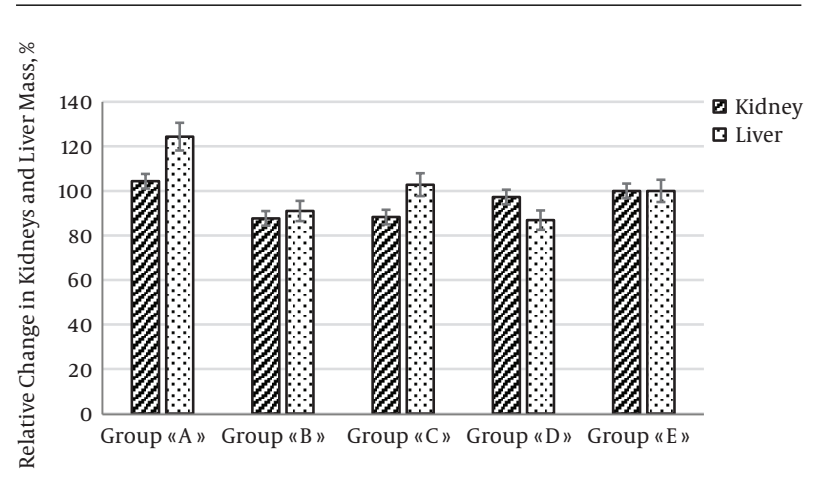

Figure 2. Weight of internal organs on the 42 nd day. Note. ${ }^{*}$ - $\mathrm{P}<0.05$ compared with group E, as $100 \%$.
On 42nd day, integral indexes of chronic intoxication of liver and kidney were increased in both animal groups A $(+43.2 \%$ and $+20.1 \%)$ and B $(+7.3 \%$ and $+31.8 \%)$ when compared with the intact control group $\mathrm{E}$ (Table 2).

\section{Discussion}

The significant effect of isotope $\mathrm{D} / \mathrm{H}$ composition on internal organs of rats, which had consumed DDW, was a finding of this research. This result can be explained by the theory of hydrogen isotope exchange reactions in macromolecules. The thermodynamic disparity of isotopic compounds can lead to uneven distribution of hydrogen isotopes at equilibrium as a result of isotope exchange reactions in the tissues, moreover, another reason is the preferred accumulation of protium or deuterium (15). Isotopic exchange reactions in biological systems may cause variations in thermodynamic and kinetic parameters of biological molecules (1). Selective changes in active and allosteric site of enzymes are associated with exchange of hydrogen isotopes in dissociating groups (-OH, $-\mathrm{SH},-\mathrm{NH}_{2}$, $=\mathrm{NH})$. This phenomenon is related to the increase of protium concentration in these groups, that is caused by modifications of enzyme conformations and can lead to change in the rate of a chemical reaction, because the activation energy of the molecule transition states in the implementation of biocatalytic reactions is reduced. Intermolecular and intramolecular kinetic isotope effects are summarized 
Sergeevich DS et al.

\begin{tabular}{|c|c|c|c|c|c|}
\hline \multirow[t]{2}{*}{ Parameters } & \multicolumn{5}{|c|}{ Experimental Animals } \\
\hline & Group A, Negative Control & Group B & Group C & Group D, Positive Control & Group E, Control \\
\hline ALT, U/L & $158.5 \pm 49.4^{\mathrm{a}}$ & $128.2 \pm 25.7^{\mathrm{a}}$ & $116.6 \pm 21.2$ & $81.5 \pm 24.3$ & $100.0 \pm 12.4$ \\
\hline AST, U/L & $142.9 \pm 25.8^{\mathrm{a}}$ & $123.8 \pm 18.1^{\mathrm{a}}$ & $127.5 \pm 14.3^{\mathrm{a}}$ & $105.6 \pm 18.4$ & $100.0 \pm 17.8$ \\
\hline Total bilirubin, $\mu \mathrm{mol} / \mathbf{L}$ & $246.4 \pm 20.9^{\mathrm{a}}$ & $179.5 \pm 49.6^{\mathrm{a}}$ & $171.6 \pm 45.1^{\mathrm{a}}$ & $161.6 \pm 25.2^{\mathrm{a}}$ & $100.0 \pm 13.1$ \\
\hline ALP, U/L & $278.0 \pm 66.2^{\mathrm{a}}$ & $224.3 \pm 27.4^{\mathrm{a}}$ & $258.8 \pm 28.9^{a}$ & $142.7 \pm 36.3^{\mathrm{a}}$ & $100.0 \pm 16.0$ \\
\hline Total protein, $\mathrm{g} / \mathrm{L}$ & $104.5 \pm 18.6$ & $98.6 \pm 16.7$ & $102.3 \pm 20.6$ & $89.0 \pm 17.1$ & $100.0 \pm 12.9$ \\
\hline Creatinine, $\mu \mathrm{mol} / \mathbf{L}$ & $157.1 \pm 29.3^{\mathrm{a}}$ & $129.3 \pm 17.2^{\mathrm{a}}$ & $140.9 \pm 16.4^{\mathrm{a}}$ & $108.7 \pm 21.6$ & $100.0 \pm 19.3$ \\
\hline
\end{tabular}

a - P $<0.05$ compared with the group E, as 100\% (ALT - $48 \mathrm{U} / \mathrm{L}$, AST - $163 \mathrm{U} / \mathrm{L}$, total bilirubin - $6 \mu \mathrm{mol} / \mathrm{L}, \mathrm{ALP}$ - $66 \mathrm{U} / \mathrm{L}$, total protein - $53 \mathrm{~g} / \mathrm{L}, \mathrm{Creatinine} \mathrm{-} 46 \mu \mathrm{mol} / \mathrm{L}$ ).

\begin{tabular}{lcccc}
\hline Table 2. Integral Index of Chronic Intoxication (IICHI) on the 42nd Day & & & \\
\hline Index & IICHI A & IICHI B & IICHI C & IICHI D \\
\hline Kidney & $0.412 \pm 0.015^{\mathrm{a}}$ & $0.355 \pm 0.008$ & $0.314 \pm 0.011$ & $0.335 \pm 0.008$ \\
Liver & $4.180 \pm 0.216^{\mathrm{a}}$ & $3.134 \pm 0.139$ & $3.088 \pm 0.125$ & $2.548 \pm 0.109^{\mathrm{a}}$ \\
\hline
\end{tabular}

${ }^{\text {a }}-\mathrm{P}<0.05$ compared with group E. IICHI for groups A, B, C, D, and E presented in units calculated by dividing weight of rat organ by the animal body weight.

in biological objects due to complexity of high-molecular compounds (proteins, nucleic acids) and their solvation capacity, and hence the isotopic exchange reactions of hydrogen between chemical dissociating groups and hydration shell of macromolecules. Such changes lead to fluctuation of energy during an enzyme-substrate interaction (intermolecular effect) and can be accompanied by different rates of intramolecular conformational rearrangements (enzyme-substrate complex) (16). These effects may lead to a decrease of time within the individual stage of biocatalytic transformation or acceleration recovery of enzyme to active form after single catalytic cycle, thereby increasing the activity of biochemical processes (17).

Presumably, DDW is able to change the speed of biocatalytic processes in cells of detoxification system organs due to reduction of activation energy of active enzymes groups. Moreover, DDW may effect transcription and protein translation by isotope exchange reactions during thermodynamic fluctuations in DNA and its hydration shell. These changes can enhance the DNA ability to interact with transcription factors, and this leads to an increase of proteins contenting in nonspecific defense systems (heat shock proteins and enzymes with antiradical activity (18)), and therefore stimulate resistance to stress influences (19), e.g. during intoxication related to hepatic-renal insufficiency. Furthermore, DDW can quickly penetrate through cell membranes and reactively derive the metabolites (20).

It was revealed that irregularities in the nonspecific defense system leads to morphological changes in detoxification organs and impair the adaptive capacity of the organism under typical pathological conditions.
Only liver IICHI in group C was higher $(+5.8 \%)$ than in group E, while kidneys' IICHI was not significantly different. This data confirmed DDW cytoprotective effect under stress conditions development of humoral and cellular defense systems by deuterium content reduction in the organism. However, the liver IICHI in group D had lower results by $12.7 \%$ compared with group E. The obtained results also indicated an increased capacity of detoxification system of animals that had consumed DDW. The highest means of liver IICHI and kidney IICHI were noted in group A: $+43.2 \%$ and $+20.1 \%$, respectively, compared to IICHI of intact group E, and were higher than similar indexes of rats that had consumed DDW.

\subsection{Conclusion}

The received data of morpho-functional status correlated with clinical and biochemical parameters in all experimental groups. The revealed correlation confirmed the possibility of DDW influence on the nonspecific defense system by isotope $\mathrm{D} / \mathrm{H}$ exchange reactions.

Dynamics of studied parameters in group D indicated that DDW did not possess cumulative effect, yet could stimulate its own effects in the chronic experiment (group C). The observed tendency can correspond with the DDW ability to influence the thermodynamic state of nucleic acids in cells as well as speed of transcription and translation. Recovery of biochemical parameters was revealed in group $\mathrm{B}$ and $\mathrm{C}$, in which animals consumed DDW before and throughout the experiment. Furthermore, DDW consumption did not increase body weight (rats of group D), there- 
fore its use is more reasonable in pathological and specific physiological conditions.

The ability of DDW to improve function of detoxification system was revealed under conditions of hepatorenal toxicity. Deuterium-Depleted Water can be applicable for correction of metabolic processes in different functional states due to isotope $\mathrm{D} / \mathrm{H}$ exchange reaction's ability to activate the non-specific defense system.

This work was supported by the Russian Science foundation (project No 15-16-00008).

\section{Footnote}

Conflict of Interests: The authors declare that they had no conflict of interest.

\section{References}

1. Bykov MI, Dzhimak SS, Basov AA, Arcybasheva OM, Shashkov D, Baryshev MG. [Comparative characteristics of the isotopic D/H composition and antioxidant activity of freshly squeezed juices from fruits and vegetables grown in different geographical regions]. Vopr Pitan. 2015;84(4):89-96. [PubMed: 26852536].

2. Magdas DA, Puscas R. Stable isotopes determination in some Romanian fruit juices. Isotopes Environ Health Stud. 2011;47(3):372-8. doi: 10.1080/10256016.2011.600454. [PubMed: 21892892].

3. Strauch G, Haendel D, Maass I, Muhle K, Runge A. Isotope variations of hydrogen, carbon and nitrogen in florae from the Schirmacher Oasis, East Antarctica. Isotopes Environ Health Stud. 2011;47(3):280-5. doi: 10.1080/10256016.2011.600455. [PubMed: 21892889].

4. Meehan T, Giermakowski JT, Cryan P. GIS-based model of stable hydrogen isotope ratios in North American growing-season precipitation for use in animal movement studies. Isotopes Environ Health Stud. 2004;40(4):291-300. doi: 10.1080/10256010410001731404. [PubMed: 15621747].

5. Walter WD, Kurle CM, Hopkins J3. Applications of stable isotope analysis in mammalian ecology. Isotopes Environ Health Stud. 2014;50(3):287-90. doi: 10.1080/10256016.2014.933214. [PubMed: 25013986].

6. Bowen GJ. Ocean science. A faster water cycle. Science. 2011;332(6028):430-1. doi: 10.1126/science.1205253. [PubMed: 21512025].

7. Bowen GJ, Winter DA, Spero HJ, Zierenberg RA, Reeder MD, Cerling TE, et al. Stable hydrogen and oxygen isotope ratios of bottled waters of the world. Rapid Commun Mass Spectrom. 2005;19(23):3442-50. doi: 10.1002/rcm.2216. [PubMed:16261651].
8. Somlyai G, Jancso G, Jakli G, Vass K, Barna B, Lakics V, et al. Naturally occurring deuterium is essential for the normal growth rate of cells. FEBS Lett. 1993;317(1-2):1-4. [PubMed: 8428617].

9. Kulikova EI, Kriuchkova DM, Severiukhin Iu S, Gaevskii VN, Ivanov AA. [Radiomodifying properties of deuterium-depleted water with poor content of heavier isotopes of oxygen]. Aviakosm Ekolog Med. 2012;46(6):45-50. [PubMed: 23457969].

10. Lisitsyn AB, Baryshev MG, Basov AA, Barysheva EV, Bykov IM, Dydykin AS, et al. [Influence of deuterium depleted water on the organism of laboratory animals in various functional conditions of nonspecific protective systems]. Biofizika. 2014;59(4):757-65. [PubMed: 25707244].

11. Lobyshev VI, Kalinichenko LP. Izotopnye efffekty $\mathrm{D}_{2} \mathrm{O} v$ biologicheskikh sistemakh. Moscow: Izd-vo "Nauka"; 1978. 214 p.

12. Ávila DS, Somlyai G, Somlyai I, Aschner M. Anti-aging effects of deuterium depletion on Mn-induced toxicity in a C. elegans model. Toxicol Lett. 2012;211(3):319-24. doi:10.1016/j.toxlet.2012.04.014.

13. Dzhimak SS, Baryshev MG, Basov AA, Timakov AA. [Influence of deuterium depleted water on freeze-dried tissue isotopic composition and morphofunctional body performance in rats of different generations]. Biofizika. 2014;59(4):749-56. doi: 10.1134/S0006350914040101. [PubMed: 25707243].

14. Basov AA, Bykov IM, Baryshev MG, Dzhimak SS, Bykov MI. [Determination of deuterium concentration in foods and influence of water with modified isotopic composition on oxidation parameters and heavy hydrogen isotopes content in experimental animals]. Vopr Pitan. 2014;83(5):43-50. [PubMed: 25816625].

15. Kreuzer-Martin HW, Lott MJ, Ehleringer JR, Hegg EL. Metabolic processes account for the majority of the intracellular water in log-phase Escherichia coli cells as revealed by hydrogen isotopes. Biochemistry. 2006;45(45):13622-30. doi: 10.1021/bi0609164. [PubMed: 17087516].

16. Dzhimak SS, Basov AA, Fedulova LV, Didikin AS, Bikov IM, Arcybasheva $\mathrm{OM}$, et al. [Correction of Metabolic Processes in Rats during Chronic Endotoxicosis using Isotope $(\mathrm{D} / \mathrm{H})$ Exchange Reactions]. Izv Akad Nauk Ser Biol. 2015;(5):518-27. [PubMed: 26638240].

17. Boros LG, D’Agostino DP, Katz HE, Roth JP, Meuillet EJ, Somlyai G. Submolecular regulation of cell transformation by deuterium depleting water exchange reactions in the tricarboxylic acid substrate cycle. Med Hypotheses. 2016;87:69-74. doi: 10.1016/j.mehy.2015.11.016. [PubMed: 26826644].

18. Finkel T, Holbrook NJ. Oxidants, oxidative stress and the biology of ageing. Nature. 2000;408(6809):239-47. doi: $10.1038 / 35041687$. [PubMed: 11089981]

19. Dzhimak SS, Basov AA, Baryshev MG. Content of deuterium in biological fluids and organs: Influence of deuterium depleted water on $\mathrm{D} / \mathrm{H}$ gradient and the process of adaptation. Dokl Biochem Biophys. 2015;465:370-3. doi: 10.1134/S1607672915060071. [PubMed: 26728727].

20. Zubarev RA. Role of stable isotopes in life-testing isotopic resonance hypothesis. Genomics Proteomics Bioinformatics. 2011;9(1-2):15-20. doi: 10.1016/S1672-0229(11)60003-X. [PubMed: 21641558]. 